\title{
Developing a Framework for Sustainable Information and Communication Technology Platforms for Resource Scarce Rural Communities
}

\section{Thato Foko}

South African Council for Scientific and Industrial Research, South Africa

Corresponding Author.

\begin{abstract}
The South African government, in an attempt to bridge the digital divide, deployed hundreds of Platforms to rural areas of the country. The purpose of this study is to use the lessons learned during these deployment to develop a framework for sustainable Platforms, normally referred to as telecentres. The ICT Platform project is the initiative of the South African government and implemented by the CSIR with the intention to provide ICTs to rural South African. For this study the Technology Acceptance Model and its extended version are utilised to framework for sustainable Platforms. The main research methodology was qualitative research with interpretivism as philosophy. The results provide the insights into what makes Platforms to attract usage and be sustainable in the long run. The study proposes a new framework called SUS-MAT where SUS relates to (i) stakeholders identification, (ii) utility of technology, and (iii) sustainability of technology. These are supported by cross cutting MAT which entails (iv) marketing, (v) awareness creation and (vi)
\end{abstract}

Foko, T. (2018). Developing a Framework for Sustainable Information and Communication Technology Platforms for Resource Scarce Rural Communities. . The Journal of Community Informatics, 14 (2), 64-84.

Date submitted: 2017-01-23. Date accepted: 2018-11-27.

Copyright (C), 2018 (the author as stated). Licensed under the Creative Commons AttributionNonCommercial-ShareAlike 2.5. Available at: www.ci-journal.net/index.php/ciej/article/view/1369 
technical support. The main discovery is the utility of technology

which is critical to any long term sustainability of any Platform.

Keywords: Telecentres, ICT Platforms, information communication technologies, technology acceptance model, sustainability, framework, economic development, qualitative research,

\section{Introduction and background}

The South African National Development Plan (NDP) (2011) vision asserts that information and communication technology (ICT) "will underpin the development of a dynamic information society and knowledge economy that is more inclusive and prosperous". The vision also talks to the seamless information infrastructure accessible to all and robust enough to enable access to services required for effective economic and social participation. This vision concretises many ICT initiatives which many government departments had been embarking on since the dawn of the country's democratic dispensation in 1994. From 2002 two government departments in collaboration with the South African Council for Scientific and Industrial Research (CSIR) had been involved in deploying ICT Platforms (Platforms) in remote areas to provide ICT access and the Internet among others, to rural inhabitants who hitherto had little or no access to these technologies.

The Platform deployments were supported by one of the government departments (the Department) and ran from 2013 to 2016 in 14 different locations country wide. The deployments were part of an initiative to develop and enhance computer skills with minimal external intervention and to provide internet and data access to communities in deep rural areas (Stillman et al. 2012). The project was again intended to allow users access to innovative ideas, leading to entrepreneurship and wider socio-economic and community development. The overarching feature of the platform was to address the issue of data access to communities in deep rural areas where it is expensive, slow and unreliable (van der Vyver and Marais, 2013). Prior to 2002 Universal Service and Access Agency of South Africa (USAASA) through its predecessor Universal Service Agency (Attwood \& Braathen 2010) was involved in providing ICT access to different communities through its network of telecentres. The success of these telecentres varied to differing degrees with some disappeared from the face of the earth while others prospered. It is, therefore the aim of this study to use all the experiences gained in deploying the Platforms to develop a framework for sustainable Platforms, sometimes referred to in this paper as telecentres.

\section{The purpose}

The CSIR was appointed in 2013 by one of the South African government department (the Department) to become the implementing agency responsible for the deployment, coordination and monitoring and evaluation of all Platforms across the country. The purpose of this paper is to use some of the lessons learned during this process to provide 
some insights into what makes sustainable ICT Platforms (telecentres) and Technology Acceptance Model (TAM) will be used to appraise and develop this framework These are reported in the Final M\&E Consolidation Report of 2016 and were used to develop the framework for sustainable Platforms. TAM is utilised to understand how users accept and use these Platforms.

\section{Sustainable technologies}

In recent times the popularity of the word sustainability can be traced to the Brundtland Commission Report, Our Common Future, defined 'sustainable development' as "development that meets the needs of the present without compromising the ability of future generations to meet their own needs" (World Commission on Environment and Development, 1987). This definition has been widely circulated and is accepted as authoritative. If this is taken as the starting point then at the heart of sustainability there lies the notion of quality future access and use. This term was further expanded in 1992 at the Rio de Janeiro UN's Conference on Environment and Development (or 'Earth Summit') where nations came together to chart "a blueprint on how to make development socially, economically and environmentally sustainable" (Johnson, 1993). Therefore, sustainability is at the core of this study. In their definition of sustainability Glatfelter (2016) asserts, "It is the process of conducting business using practices that protect and enhance the environmental, social and financial resources needed by future generations to enjoy a life equal to or greater than our own".

In terms of sustainable technologies these "rely on resources that are either renewable or so abundant that we can treat them as such" (Population Matters, 2017). Population Matters further explains that technology can be considered sustainable if through its use there are no serious long term environmental impacts. Therefore, container solar powered Platform is considered among others to be a sustainable technology hub and this paper attempts to understand what makes these technologies sustainable besides being solar operated and environment friendly. This includes social, financial and economic sustainability.

The paper will first review literature on telecentres including the different deployment models. Secondly, the conversation will be on the deployment of Platforms and what that entails. Thirdly, the technology acceptance model will be discussed as the favoured conceptual framework. The forth section will highlight the problem statement which will be followed closely by a section on methods and tools used in gathering of data. These will be followed by sections covering the results, the analysis of such results and lastly the conclusion.

\section{Review of telecentres}

At the beginning of the $21^{\text {st }}$ century most rural areas generally had poor fixed network infrastructure and communities were poorly connected to the Internet making its access a great challenge. Private, government and civil society attempted to come up with different models of access to ICTs in order to transform these communities into intelligent and highly skilled environments capable of working as potential sources of 
labour and innovation. There are many different telecentre definitions but the one that is utilised in this writing is the one proposed by Zongo (1999) which states that a telecentre "is a place where public access to communication and information for economic, social and cultural development is provided". This definition encapsulates the reason why the government of South Africa pushed for establishment of telecentres particularly in the country's rural settings.

This paper attempts to develop a framework for sustainable TCs by looking at a number of them and to ascertain what makes some to work well while others are not. Some contribute meaningfully to social and economic development of a given community. South Africa adopted a telecommunications policy of universal service and universal access in 1996, by means of the Telecommunications Act No 103 of 1996 which brought into existence the Universal Services Agency (USA). This was mandated to establish telecentres across the country (Lesame, 2006). According to Lesame between 1996 and 2005 South Africa established 133 telecentres across the country. These TCs could be operated on commercial bases or non commercial run by community organizations as non-profit (Attwood \& Braathen, 2010).

Although telecentres have been around for many years, they are still undervalued "tools of integrated local economic development, rural development, economic empowerment and socio-economic development in general" (Breitenbach, 2013). In the mid-1990s the South African government through its agency Universal Service and Access Agency of South Africa (USAASA) deployed telecentres across the country. When telecentres (TCs) were first introduced in South Africa the idea was mainly to bridge the digital divide by providing access to ICTs to people living on the margins of information society and residing mainly in peri-urban and rural communities. "A Universal Service Fund (USF) was established along with the Universal Service Agency (USA)" (Lesame, 2006). The USA was later renamed USAASA in 2005 (Attwood \& Braathen, 2010). Here the assumption is that once established people would embrace, adopt and use them for their own development. So much emphasis was placed on ICTs because they were considered the core of growth and development of any country and central to enhancing efficiency and people's development (National Planning Commission, 2011). One of the reasons behind this government intervention was that technologies have the capacity to enhance lives of ordinary people once they have embraced it and learned the best ways to use it. "A typical telecentre refers to a place providing connectivity and access to information via a range of information and communication technologies including phone, fax, computers and the Internet” (Bailur, 2007).

Literature indicates that there are many different types and models of telecentres to learn from and to understand what makes one a sustainable telecentre. There are a number of examples where TCs have been successful because their sustainability was put at the centre from the planning stage. Proenza et al. (2001) identifies two main types of telecentre projects with the first being just the micro-enterprise telecentres or small phone shops, which have flourished in many parts of Africa, Asia and Latin America. The business models of these centres is to provide basic telephone services and fax and Internet services to communities and are run by small entrepreneurs who are mostly successful in generating revenue. The second type of telecentres which is the topic for 
this paper provides a broad scope to support socio-economic development by facilitating the provision of a wide variety of public and private information-based goods and services to rural communities. In the South African context these are called multi-purpose community telecentres.

However, for the purposes of this paper telecentres are broadly divided into three distinct models with overlapping functions and these are: (i) private enterprise, (ii) government supported, and (iii) public-private partnership (Fig. 1 below).

(a) Private enterprise model: Telecentre as a private enterprise focuses on the creation of new job-opportunities among other core duties. It is not their primary objective to contribute on the regional development (Falch \& Anyimadu, 2003). The business owners attempt to create a space where (i) entrepreneurs meet other entrepreneurs; (ii) they provide business support; and (iii) access to practice and critical thinking. (Bailey \& Ngwenyama, 2013).

(b) Government support: The role of government is to provide (i) support for services; (ii) business development; and (iii) networks for business development.

(c) Public-Private Partnerships: In the realm of e-governance it is the responsibility of government to deliver services to the citizens. The private partner's role among others is to invest in application software design, development, implementation and operation. These allow both partners to carry on with their core-mandate.

The sustainability of these different types still varied. Below are some of the examples of sustainable TCs. 


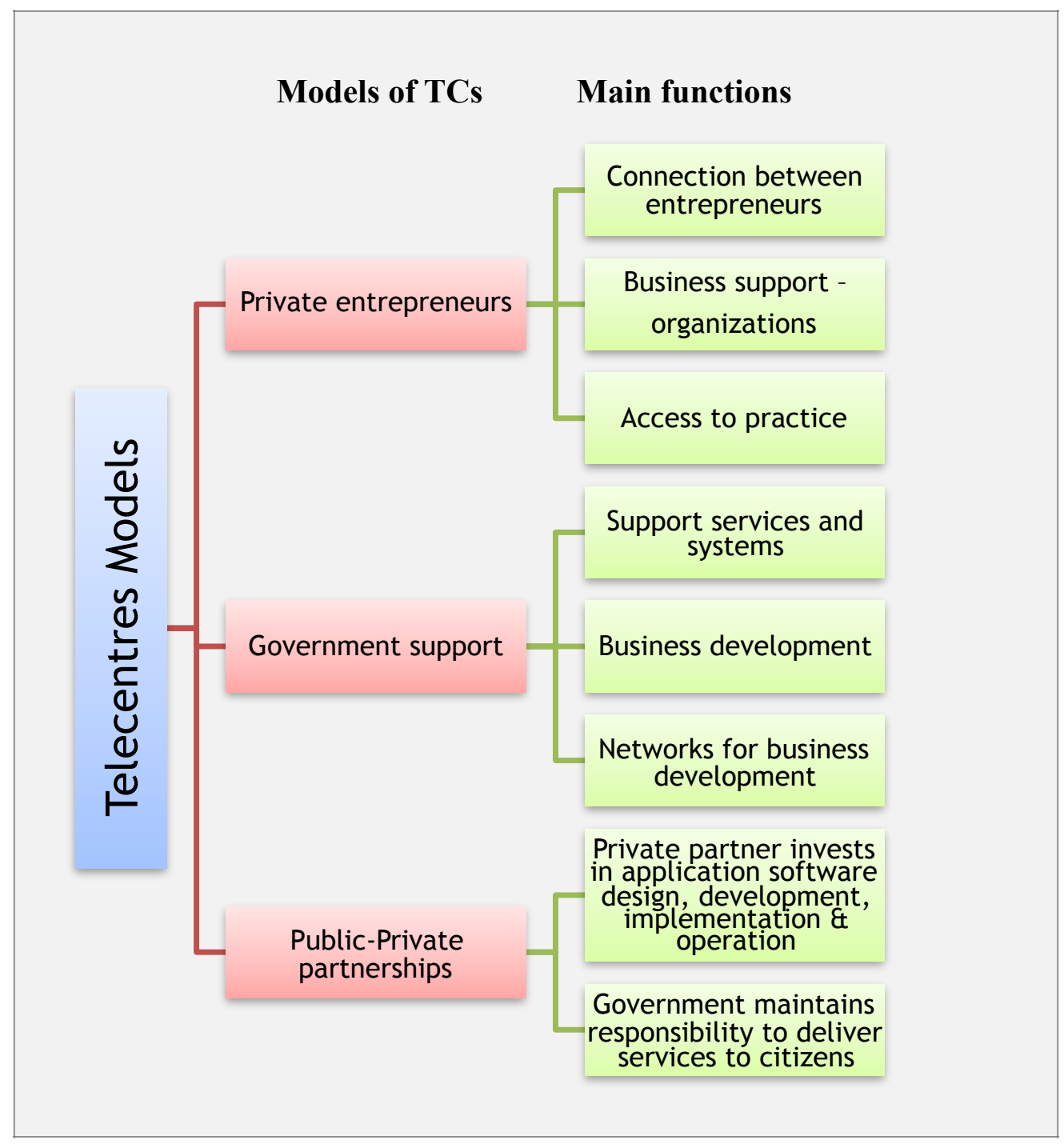

Figure 1: Three different models of telecentres and their functions

\section{Some examples of sustainable TCs}

\section{Akshaya Telecentre Project in Kerala}

Two examples are the Akshaya Telecentre Project in Kerala, southern India and EasySeva. The Akshaya project is one example of a government attempting to develop a sustainable TC by bringing on board the public sector, private sector and civil society actors (Madon, 2005). The Kerala government was deliberate in depicting Akshaya as a social development project targeted at citizens through the local village councils. According to Madon, the Akshaya project was launched with the overall aim of not just provision of access but also of creating economic growth and generating employment in the region where many people were not employed. ICT access, skills development and provision of relevant content were identified drivers to economic growth and employment. For sustainability of TCs, relationships between a number of players including private entrepreneurs, government, international donors, business, telecommunications suppliers, civil society organisations and individual community members play a big role. 


\section{EasySeva}

Another TC project is the Sri Lankan project called an EasySeva, an innovative franchise model involving both local and international partners (Hosman, 2011). Hosman states that EasySeva project tried to use the public-private partnership (PPP) model to enhance people's lives by providing unique services such as online banking, money transfer, loan applications, bill payment, appointment booking, technical skills courses, and small-group training. The success of EasySeva depended on identification of partners and experience, motivation, commitment of staff, and differentiation of services. Other important elements included provision of incentives for partner commitment, marketing and sharing of ideas.

\section{NenaSala}

There are other examples in Sri Lanka such as the Sri Lankan telecentre network model NenaSala started in 2004, a collaboration between Intel and Sri Lankan Information and Communications Technology Association (ICTA). Through the Nenasalas women and youth were given empowerment opportunities. "A successful telecentre with access for everyone should be organised and designed by someone belonging to the telecentre movement" (Hansson et al., 2010).

\section{ICT Platform project}

The first Platform was established in 2002 and the idea was address the issue of data access to communities in deep rural areas where it was expensive, slow and unreliable (van der Vyver and Marais, 2013). These Platforms were deployed in all the country's nine provinces and sites were either located at municipal offices or tribal authority offices. The project envisaged a network of over a 1000 Platforms with the footprint reaching even the remotest areas of South Africa. "This self-sustaining community technology hub provides wireless connectivity for PCs, mobile phones, laptops and printers, as well as solar power and satellite connectivity, and mesh networking" (Smith, 2012). Smith states that this began as a one sitter computer terminal in 2002 and by the end of this phase more than 40 computers had been deployed. From 2007 three sitter (Fig. 2 below) and four sitter machine were deployed and by 2012 "Some 230 systems have already been deployed in South Africa" more than 32 had been installed abroad.

The current phase of the project is the container Platform with solar power, satellite connectivity, and mesh networking. The deployments of the container solar-powered Platforms began in 2014 and were installed on 14 sites across the country at the following sites: Ebenhaezer, Luwamba, Vukuzakhe, Marapyane, Sokhulumi, Devon, Wupperthal, Moretele, Verdwaal, Tswelopele, Dannhauser, Matlakeng, DonDonald and Sedibeng and their locations are indicated in the map below. It is reported in the consolidated report (2016) that the aim of the container Platform project was to roll out Platforms for the following purposes: (i) As information and communication resources; (ii) As learning centres; (iii) As access points to Information and Communication Technologies (ICTs); (iv) As practical tools for development; and (v) As a tool for Bridging the Digital Divide. The Platform is underpinned by "the idea of people's inherent cognitive ability to teach themselves computer skills with minimal external intervention". For this to take place computers must be easily accessible to potential 
learners, this include everyone in the community, in an environment conducive for experimentation (Smith et al. 2006). The Platform consisted of the solar-powered housing (Fig. 3 below) which provided access for people to the robust computers and mobile tablets and these two are the actual Platform (Consolidated Report, 2016). The accessories to the Platform included among others printers, photocopier and Fax machines. The Platform included huge amounts of content which was accessible without connecting to the Internet. The Platform contained a cached version (stored locally) of the 2007 Wikipedia and direct internet in public places with the purpose of offering free 24-hour access to the technology to underserved, poor populations (Stillman et al. 2012). This is an encyclopaedia resource for obtaining information on a wide range of topics. Users were able to watch video clips stored on the platform. The content provides useful information on a wide range of subjects from classroom resources such as past exam papers, to agricultural information and maths and science tutorials.

This endeavour has benefited many South Africans who by accessing information via these platforms became part of the information society. The Platforms were at the heart of the increased numbers of people visiting among others Multi-Purpose Centres where some were deployed. The installation of and free access to the Platforms ensured that Multi-Purpose Centre saw an upsurge in their utilisation by community members particularly in areas where users' numbers had been dwindling for a while.
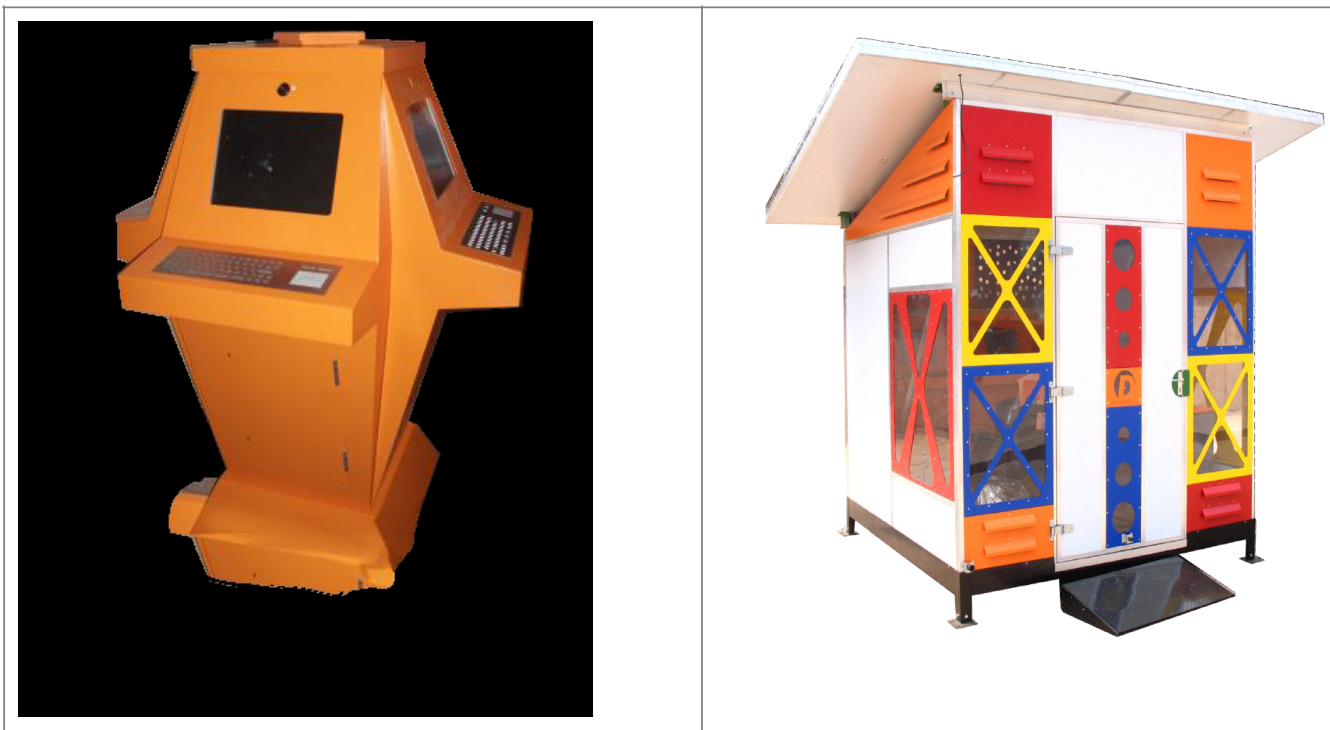

Fig. 2: Three Terminal standalone ICT Platform (2015)

Fig. 3: Solar-powered container ICT Platform (2015) 


\section{Conceptual Framework: TAM}

For this particular study we intend to use the Technology Acceptance Model which attempts to focus on how people adopt and utilise a particular technology introduced to them. TAM was developed by Davis in 1986 and then extended by him in 1979, Venkatesh in 2000 and many others. The goal of TAM is to provide clarification on the factors regarding computer acceptance that is general, this should be able to also explain user behaviour (Davis, 1989).

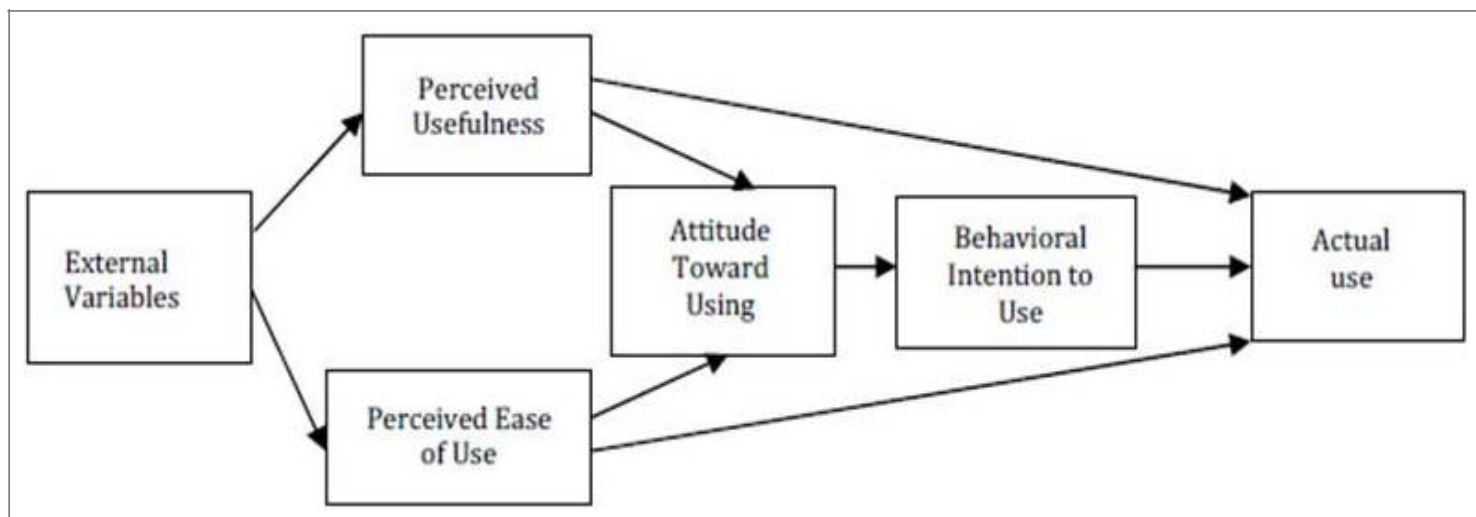

Fig 4. The Technology Acceptance Model (TAM)

TAM is an information systems theory that looks into how users accept and use an information technology on the bases of its perceived usefulness and ease of use (Davis, (1989). This model attempts to explain how and when the users will embrace the technology. It suggests that when users are introduced to a new technology system a number of factors would influence their behaviour or decision to adopt and use it. "The goal of TAM is to provide an explanation of the determinants of computer acceptance that is general, capable of explaining user behaviour across a broad range of end-user computing technologies and user populations, while at the same time being parsimonious and theoretical" (Davis, 1989). At the centre of TAM is the need to provide guideline of or tracing the impact on the external factor, on attitudes and intentions. Therefore, this model has become a widely applied model for users' acceptance and usage of new technologies (Bertrand \& Bouchard, 2008).

\section{Extended TAM}

Many scholars within the field of ICT have found TAM as not all encompassing of many other technologies and their usage and therefore included other elements to extend it. Those who extended TAM include Shih (2003) (Fig. 5 below) who wrote about the behaviour of enterprise Intranet users; Choo (1998) proposed information behaviour model into TAM "to explain how people reduce task uncertainty via the information needs-seeking-use cycle" (Shih, 2003). For instance, Sun, Wang and Cao integrated "trust related construct ('perceived credibility') and two resource-related constructs ('perceived self-efficacy' and 'perceived cost') into the TAM to analysing adoption behaviour of mobile commerce (MC)". The construct of subjective norm was included by Venkatesh and Davis (2000) to accommodate the social influences. The 
belief and attitude toward behaviour (in Fig. 4 below) assume the rational decision making of an individual are the basic pillars of the extended TAM.

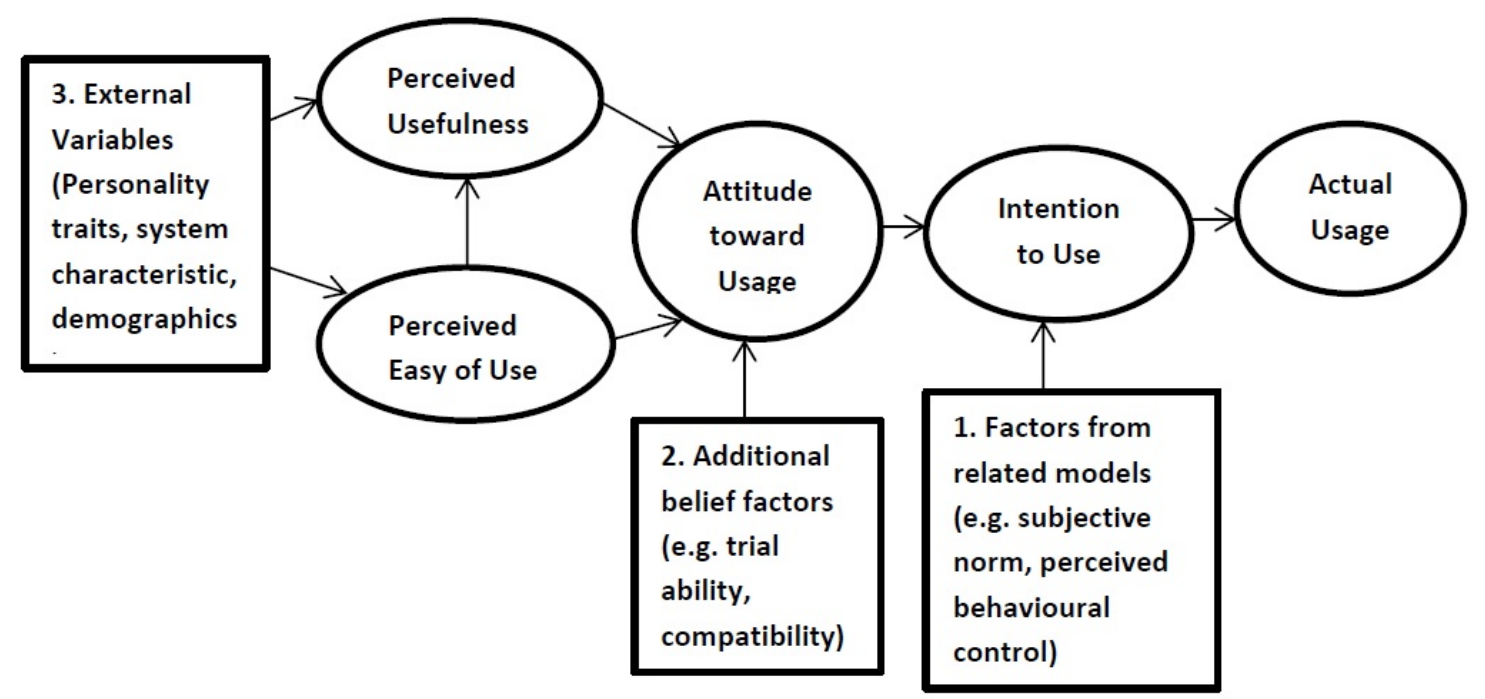

Fig. 5: The Extension to TAM as adapted by Wixom and Todd (2005) from Long Li (2010)

\section{Critic of TAM}

TAM assumes that there are only unidirectional causal relationships among the major variables within this model ( $\mathrm{Li}, 2010)$. With regard to the perceived usefulness, TAM assumes that the intention to use the technology can be predicted once the individual thinks the technology is useful (Davis, 1989). However, there is no empirical evidence found to support any correlation between perceived usefulness and behaviour intention (Lucas \& Spitler, 1999).

The same applies to the perceived ease of use and actual use of the technology whereby no empirical evidence is found to confirm any relationship (Chau, 1996). Chau and $\mathrm{Hu}$ (2001) stated, "Contrary to the assertion of TAM ... perceived ease of use was not found to have any significant effects on perceived usefulness or attitude". In contrast, some researchers talk about Social Cognitive Theory as a more applicable theory to use as it gives prominence to the concept of self-efficacy (Compeau et al., 1999). Bandura (1994) explains self-efficacy as people's beliefs in their abilities to perform any chosen duties which influence and affect their lives. Bandura further explains, "Self-efficacy beliefs determine how people feel, think, motivate themselves and behave". Selfefficacy is defined as the judgment of one's ability to use a technology to accomplish a particular job or task (Compeau \& Higgins, 1995).

\section{Methodology}

This paper attempts to develop a framework for sustainable Platforms (telecentres) by looking at a number of them and to ascertain what makes some to work well while 
others are not. The main research methodology will be qualitative multiple case study research with interpretivism as philosophy. "Interpretive methods start from the position that our knowledge of reality, including the domain of human action, is a social construction of human actors" (Walsham, 2006). These methods support our research paradigm because of their flexible use, particularly with technology, while allowing future developments. The research employed interpretive methodologies whereby interpretive is grounded in the social sciences and it accepts the notion that individuals create meaning within a specific knowledge domain (Hanson, 2008). The qualitative methods were chosen in order to assist in our understanding of how people accepted and used new technologies based on TAM and the methods included telephonic interviews, questionnaires and observations.

For this study ainly qualitative data methods were used. Qualitative data collection instruments, "analysis, interpretation, and report writing differ from the traditional, quantitative approaches" (Creswell, 2014). Creswell explains that qualitative data encompasses examining the study sample and the general actions necessary for data collection and recording. Furthermore, it talks to the data analysis steps and methods used for presenting and interpreting data, how it's validated and the possible study outcomes. Creswell indicates that at the core of the qualitative approach is the space it creates for comments by the researcher about their role and strategies they used. Creswell further elucidates that the methods section should also include comments about the nature of the final written product due to the varying structure of qualitative projects.

Again, for this study rich data were collected using desktop methodology. "The deskbased research comprised the examination of existing literature on review methodologies, to help situate this current study within the context of existing evidence" (Rickinson \& May, 2009). Here the objective was to ascertain how telecentres were set up to contribute to the social and economic development, and what made them sustainable. Rich data were also collected using the 2016 Final Consolidated Monitoring and evaluation report which looked mainly at the container Platform. The results are based on the findings from the 14 sites of Ebenhaezer, Luwamba, Vukuzakhe, Marapyane, Sokhulumi, Devon, Wupperthal, Moretele, Verdwaal, Tswelopele, Dannhauser, Matlakeng, DonDonald and Sedibeng. These results provide some insight on what makes a successful Platform or telecentre.

\section{Results and analysis}

There are two kinds of results reported here below. The first set of results was derived from the analysis of the Platforms as reported in the "March 2016 Final Consolidated Monitoring and evaluation report". The second set of results is derived from the different telecentre case studies from a few countries. All of results were analysed in order to develop a framework for sustainable Platforms or telecentres. What made the Platforms successful is the question which the results addressed?

\section{ICT Platform - Results}




\section{Champions}

The Platform champions were an important component of the success. The study shows that the level of use was enhanced where champions: (a) felt responsible for the maintenance of the Platform; (b) felt motivated by the support from the community and the government departments involved and reported to work daily; (c) lived in the areas where the Platform is installed and they did not rely on public transportation.

The champions were able to carry out the following duties diligently: (i) reported technical failures on time and not ignored the problems; (ii) learned to fix some of these problems; (iii) ensured that the Platform and its surroundings were clean; (iv) ensure that other supporting resources such as printers and faxes were properly used and where refills were needed they were sorted timeously.

These indicate that the champions had the requisite resources and opportunities which affected their behavioural control leading to the drive to do their work properly. These champions were highly motivated to perform their duties.

\section{Community support}

The success of the Platform also relied heavily on the support derived from the community. This means that Platforms was successful where there was: (a) strong evidence of community support; (b) strong feeling of community ownership of the Platform; and (c) encouragement to use them from other community members; (d) strong evidence of creation of social ties among users. The Platform became a place where likeminded people met and socialised.

Therefore, the success of platform relied heavily on the support derived from the community who in some cases provided their own resources to ensure that Platforms were running smoothly. This involvement indicated the presence of requisite resources and opportunities necessary for users to perform as expected.

\section{Community leaders}

The success was also realised in most communities where community leaders: (a) understood the importance of, accepting and supporting Platforms; (b) were involved in awareness campaigns; and (c) promoted the use of these Platforms.

Therefore, the success of Platforms depended on the level of engagement by the community leadership in the actual promotion and awareness creation of Platforms.

\section{Marketing and awareness creation}

It was discovered that there was a strong need to market these Platforms and to create awareness around their offerings. There was a need to: (a) develop and disperse printed materials (pamphlets, signage, posters, etc.) to communicate what the Platforms were all about including the services they offered. (b) Involve all stakeholders, including community leaders in the creating awareness and marketing of these Platforms.

\section{User considerations}

Besides all that is covered above, it was discovered that Platforms were successful where users felt that the following were addressed: (a) Time challenges: Time 
restrictions in cases where the opening and closing were not in sync with the community's daily activities created major problems; (b) Reliable connectivity: Less usage of Platforms happened in instances where Platforms were supposed to have the Internet but the connectivity was unreliable; and (c) Location: There were instances where Platforms were not easily accessible as they were housed locked up in premises such as municipal offices when most people had time. This points out to the challenge of site selection.

The results show that Platforms were successfully utilised where champions, community members and leaders, and users played a supportive role. This success was realised where Platforms were marketed and awareness was created.

\section{Other case study results}

The second set of findings is derived from the analysis of literature of some of the successful telecentres just to understand what made them successful and were classified into three groups mainly: (i) Privately supported, (ii) Government supported or (iii) Public-Private Partnerships.

\section{Privately supported TC:}

Here we looked at the study carried out by Bailey and Ngwenyama (2013) titled "Toward Entrepreneurial Behavior in Underserved Communities: An Ethnographic Decision Tree Model of Telecentre Usage". The research attempted to discover how telecentres were used as areas where users could develop and enhance their entrepreneurial skills. Through this case study authors investigated the decision-making process of community members when using telecentres for entrepreneurial endeavours and to determine the enablers to economic activity.

Twenty five telecentre users from 17 to 37 years of age were identified for this purpose and were given training in a number of areas of business development like radio broadcasting, computer repair, word processing, data entry and website development, video production. Their artistic skills were also enhanced with creative writing and visual arts. From this study the following are the lessons learned:

The lessons were similar to those already indicated above. These included: (a) motivation to earn income by users who used facilities to promote their newly established businesses; (b) where social ties were built by users and community members. These increased the recognition of opportunities for entrepreneurial activities among others; (c) convenient location-proximity of TCs to where users stayed; (d) TCs staff's effective and efficient service provision; and (e) Relevant and unique services offered by telecentre.

These results show that telecentres' success also depended on usage where private interests were the driver for their success.

\section{Results on government supported}

In order to try to understand the reasons leading to the decline in numbers of telecentres operating in South Africa and causes we reviewed the studies by Attwood and Braathen 
(2010) on "Telecentres and poor communities in South Africa: What have we learnt". They explained that the Universal Service and Access Agency of South Africa (USAASA) established 65 telecentres in RSA between 1997 and 2000. An evaluation carried out in 2001 showed that $32 \%$ of these were not operating or were shut down. Another evaluation revealed that less than a third (29\%) of TCs was able to answer their phones in 2010. From their study the following are the lessons learned:

(a) Low usage. They discovered that a great deal of effort was placed on the physical rolling out of telecentres with focus being on access in the physical sense and not on people's needs; (b) lack of consideration of local requirements; (c) lack of proper record keeping of users, of usage or even of little impact taking place; (d) lack of systematic needs analysis in establishing these TCs; (e) poor salaries or incentives for TC staff leading to high staff turnover; (f) lack of technical and administrative skills; and $(\mathrm{g})$ poor access due to long distances people have to travel.

\section{Results on Public-Private Partnerships}

Another case study looked at was that of Hosman (2011) "Making the transition from pilot to scale: examining sustainability and scalability issues in a public-private telecenter partnership in Sri Lanka" where the EasySeva project was carefully studied. The EasySeva tried to use the public-private partnership (PPP) model to enhance people's lives by providing unique services such as online banking, money transfer, loan applications, bill payment, appointment booking, technical skills courses, and smallgroup training. The lessons learned in this public-private partnership included:

(a) the ability to identify good partners with appropriate experience and motivation; committed staff who offer unique services to the community; (b) commitment of TC staff; (c) differentiation of services; (d) societal issues such as involvement of women in the project; (e) publicity and awareness-raising campaigns; and (f) provision of incentives for partner commitment, marketing and sharing of ideas, challenges.

\section{New recommended telecentre framework}

The above results led to the emergence of a new framework which is developed from analysed usage of ICT Platforms and TC case studies vis-à-vis TAM. This framework is influenced by Masiero (2011) who proposed a new paradigm for telecentres studies in which social and financial sustainability are interlined by mutual reinforcements. The new framework includes the utility of technology derived from TAM. This utility of technology has been missing all along even though it acts as a magnet drawing people to TCs is added to the framework. The proposed framework is called SUS-MAT and has three standing pillars (SUS) and three cross cutting themes (MAT). SUS relates to the three standing pillars, namely (i) stakeholders identification, (ii) utility of technology, (iii) sustainability of technology while $M A T$, which cuts across all SUS, entails (iv) marketing, (v) Awareness creation and (vi) technical support (see Fig. 6 below).

For any ICT Platform or telecentre to be sustainable, the above mentioned SUS-MAT has to be satisfied. The SUS-MAT is described in detail (Fig. 6) below and the different elements which need to be considered and satisfied in order to have a sustainable TC are 
demonstrated. This framework does tries to incorporate some aspects of the extended TAM but relies more on TAM in its original form.

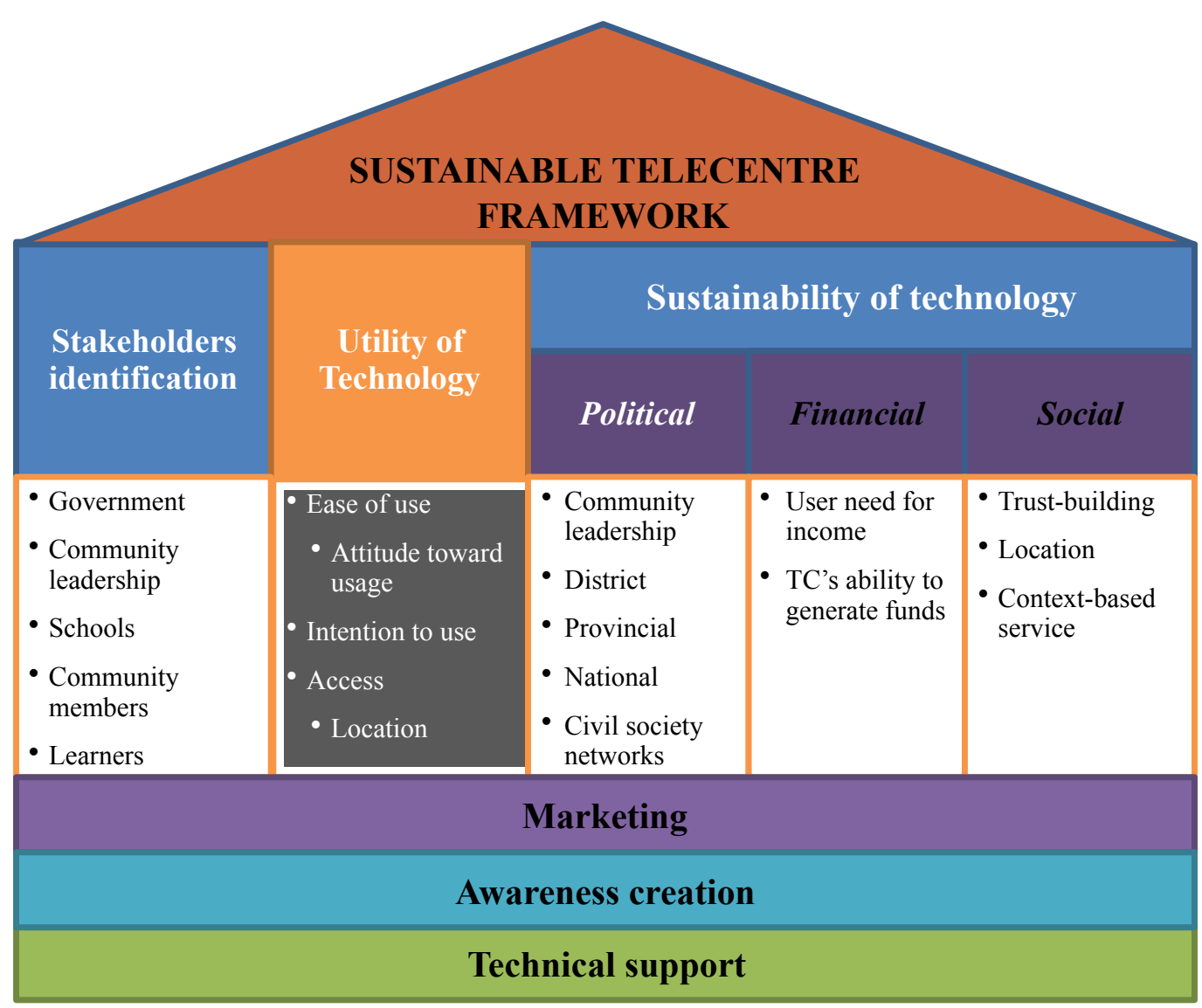

Fig. 6: describes the proposed SUS-MAT framework for sustainable Platforms (TCS)

\section{Pillar 1: Stakeholder identification}

"A project is successful when it achieves its objectives and meets or exceeds the expectations of the stakeholders" (Watt, 2014). Any project to be socially and financially sustainable has to meet the needs of a specific community (Masiero, 2011). This entails proper identification of stakeholders and the understating of their roles. Once this is achieved this managers of TCs have to rely on them and a number of mechanisms namely trust-building, a context-based service provisions and civil society involvement to ensure that the deployment and the actual usage go smoothly.

\section{Pillar 2: Utility of Technology}

The new element is the utility of technology as understood through the use of TAM. TAM is an information systems theory that looks into how users accept and use an information technology on the bases of its perceived usefulness and ease of use (Davis, 1989). Where people are not able to use the provided technology, leading to easy 
access, it would not be easy to attract them to the telecentre. This utility of use is what brings people back to the technology. Once the technology is perceived to be easy to use and accessible the attitude towards its usage softens even in instances where there are doubts and adoption follows.

\section{Pillar 3: Sustainability of technology}

The survival of telecentres over a long term depends crucially upon economic, social and political relations between many different actors (Madon, 2005). Growing the business responsibly and continuously attempting to improve financial performance can lead to great success. At the same time the concern for current and future growth of the Platforms and other telecentres and the way they uplift the lives of the people who have access to them is a critical part of their sustainability. Sustainability of technology has three components to it which are financial, socials and political crucial elements.

\section{Telecentres vs financial sustainability}

Again, telecentres have to be financially sustainable which is seen to occur when a project achieves revenue equal to or greater than the expenditure and economic return of the project. In other words, the financial sustainability of telecentres focuses on the extent to which a telecentre project is able to generate funds for recuperating capital outlay and for operating cost Harris et al. (2003). Therefore it is important to understand models of ownership which allow access and profit to reside together for the purposes of sustainability.

\section{Telecentre vs social sustainability}

For telecentres to be effective they have to be socially sustainable. The positive impact of telecentres on the social and economic development of local communities is the basis to social sustainability. This can be achieved if the local community identifies access to ICTs as the priority equal to other priorities such as clean water, better roads or better quality seeds (Grace et al. 2004). Some of the social factors may relate to time, age, occupation, gender, etc. and mechanisms have to be found to increase numbers of women involved in ICT usage.

\section{Telecentres vs Political sustainability}

Linked to financial and social sustainability is the need to ensure that a telecentre is politically sustainable (Madon, 2005). Madon argues that telecentres struggle where there is a weak link between the centre and local political bodies. Locally initiated and run TCs have better success. If telecentres have a buy-in from politicians and community leaders they tend to become resourced and become financially sustainable. Therefore as seen in the results above there is a need for strong link between TCs and local political bodies in order to strengthen them.

\section{Marketing of TCs}

Marketing and awareness creation go hand in hand as they are both intended to attract people to the TC. Marketing TCs and their different service offerings is critical to their sustainability. Marketing does not need to be done by big corporations only but it should 
be what everyone does when involved in any purposeful activity (List, 2003). He further states that interaction creates more interaction. In many situations the majority of TC users hear about telecentres from their friends. However, the support of the TC's staff will enable increased recognition of opportunities by users leading to more attraction to TCs.

\section{Awareness creation}

The raising of awareness about TCs and their offerings is crucial to the continued use of these TCs. This helps with effective utilisation by community members. This can be done thorough local workshops and training opportunities addressed to potential telecentre users. Bearing this in mind, it is crucial to nurture good social relationships between staff, users and the general community of where TCs are sited. "Creating relevant services and raising awareness about the existence and value of those services are necessary but probably not sufficient conditions for effective telecentre use and community participation in telecentre activities" (Roman \& Colle, 2002). Roman and Colle stated that the biggest impediments to the use of telecentres are: (i) awareness of their existence, and (ii) awareness of specific benefits accruing from their use.

\section{Technical Support}

Technical support: Sustainability of TCs also hinge on the availability of technical support. This involves investing in staff training so that they can provide support: (i) to different applications and services; and (ii) troubleshooting. "Investment in training is a measure of human-resource sustainability" (Whyte, 2000). This is important due to the nature of ICT technologies and the rapid nature of their changes leading to their obsoleteness. The age of the technology used is not as important as the understanding of a clear pathway ensuring its technological sustainability.

Therefore, the framework sustainable Platforms envisages (i) identification of stakeholders, (ii) utility of technology, (iii) sustainability of technology, marketing, awareness creation and social and technical support. If any one of these elements is missing the highest quality of functionality of the TC will be compromised and leading in some cases to the demise of the TC. For example, where there is no social support or the services are not context based the community is bound to stay away from the TC as it does not address its needs.

The results also have a bearing on TCs' role in community building networks which are intended to bond households and communities together. The information needs and priorities of TC users are not static and require continuous monitoring. These networks have to work towards the community's need for sharing of innovative ideas, challenges and solutions, with others in the same situation in a non-competitive manner but rather a collegial way.

\section{Conclusion}

For any ICT Platform or telecentre to be sustainable, the above mentioned SUS-MAT has to be satisfied. The stakeholders have to be properly identified and understanding of 
their roles clarified. The long term sustainability is dependent on the involvement of the communities at TCs' inception and throughout their existence. The utility of technology which is the fundamental finding of the study is crucial. This means that it is easier to attract people to TCs if they find the technology to be accessible and user friendly. The survival of TCs over a long term depends crucially upon economic, social and political relations between many different actors. It is equally important that the TC is marketed properly and awareness creation campaigns are organised. The availability of technical support for both users and champions is another important element of sustainability.

\section{Acknowledgment}

This work acknowledges the Platform project, which is supported by the one South African government department and the CSIR Platform team of Meraka for allowing us to collect data from the participants in the different provinces, which has enabled us to put our experiences together in the form of this article. Special recognition has to be given to all the role players the team interacted with in the various rural communities, including among others, the government officials, community leaders, local communities, learners and parents and all who have embraced this initiative and became co-creators of their own destiny. Last but not least our gratitude also goes to the anonymous reviewers whose comments have enhanced the quality of this work.

\section{References}

Attwood, H. \& Braathen, E. (2010). Telecentres and poor communities in South Africa: What have we learnt? Paper presented at the Chronic Poverty Research Centre (CPRC) Conference, (2010) 'Ten years of 'war against poverty', What we have learned since 2000. What we should do 2010-2020. (2010). Manchester, UK September 8-10 2010. Retrieved January 23, 2017 from http://www.chronicpoverty.org/uploads/publication files/ attwood braathen $\% 20$ telecentres.pdf

Bailey, A, \& Ngwenyama, O. (2013). Toward Entrepreneurial Behavior in Underserved Communities: An Ethnographic Decision Tree Model of Telecenter Usage. Journal Information Technology for Development archive, 19 (3), 230-248. Retrieved January 23, 2013 from http://dl.acm.org/citation.cfm?id=250377

Bailur, S. (2007) Using Stakeholder Theory to Analyze Telecenter Projects, The Massachusetts Institute of Technology Information Technologies and International Development, Vol. 3(3) spring 2006, 61-80.

Bandura, A. (1994). Self-efficacy. In V.S. Ramachaudran (Ed.). Encyclopedia of human behavior. Vol.4. Pp. 71-81. New York: Academic Press.

Bertrand, M. \& Bouchard, S. (2008). Applying the technology acceptance model to VR with people who are favourable to its use. Journal of Cyber Therapy \& Rehabilitation, vol. 1, I. 2, Summer. in press.

Breitenbach, M.C. (2013). Telecentres for sustainable rural development: Review and case study of a South African rural telecentre, Development Southern Africa, Vol. 30, No. 2

Chau, P. \& Hu, P. (2001). Information Technology Acceptance by Individual Professionals: A Model of Comparison Approach, Decision Sciences, Vol.32(4), pp.699-719.

Chau, P. Y. K. (1996). An empirical assessment of a modified technology acceptance model. Journal of Management Information Systems, 13, 185-204. 
Choo, C.W. (1998). The Knowing Organization., Oxford University Press, New York,.

Compeau, D.R., \& Higgins, C.A. (1995). “Computer Self-Efficacy: Development of a Measure and Initial Test,” MIS Quarterly (19:2), pp. 189-211.

Creswell, J.W. (2014)._Research Design Qualitative, Quantitative, and Mixed Methods Approaches (4th ed., p. 304). Thousand Oaks, CA: SAGE Publications.

Davis, F.D. (1989). Perceived Usefulness, Perceived Ease of Use, and User Acceptance of Information Technology, MIS Quarterly, Vol. 13(3) 319-340. Retrieved March 24, 2013: from http://www.jstor.org/stable/24900

Davis, F.D., Bagozzi R. P. \& Warshaws, P.R. (1989). User acceptance of computer Technology: A comparison of two theoretical models. Management Science, 35(8), 982-1003

Falch, M. \& Anyimadu, A. (2003). Tele-centres as a way of achieving universal access: the case of Ghana. Telecommunications Policy, (27) 1-2, 21-39.

Glatfelter. (2016) Meeting your needs today while building a better tomorrow. Retrieved 16 September, 2016 from: http://www.glatfelter.com/sustainability/commitment/ understanding_sustainability.aspx

Grace, J., Kenny, C. \& Qiang, Z. C. (2004). Information and Communication Technologies and Broad-Based Development: A Partial Review of the Evidence. Washington, DC: World Bank.

Hanson, J.D. (2008). Incorporating the human element: The role of interpretive research in operations management. POM 19th Annual Conference, La Jolla, California, USA, May 9 $-12,2008$

Hansson, H., Mozelius, P., Gaiani, S., \& Meegammana, N. (2010). Women empowerment in rural areas through the usage of telecentres - a Sri Lankan case study. In 2010 International Conference on Advances in ICT for Emerging Regions (ICTer) (pp. 5-10). Colombo, Sri Lanka.

Harris, R. Kumar, A. \& Balaji, V. (2003) Sustainlable Telecentres? Two cases from India. In The Digital Challenge: Information Technology in the Development Context, pp. 124-136, Ashgate, Aldershot, Hants.

Hosman, L. (2011). Making the transition from pilot to scale: examining sustainability and scalability issues in a public-private telecenter partnership in Sri Lanka. Information Technology for Development, (17) 3 , 2011 Special Issue: Information Technology Success Factors and Models in Developing and Emerging Economies. Retrieved March 24, 2013, from http://www.tandfonline.com/doi/abs/10.1080/02681102.2011.568225\#.UtZrhxCSx1Y

Johnson, S.P. (ed.) (1993) The Earth Summit: The United Nations Conference on Environment and Development. London: Grahm and Trotman

Lesame, Z. (N.d.), Telecentres and sustainable community development in South Africa, Department of Communication Science, University of South Africa, College of Human Sciences. Retrieved March 24, 2013, from http://www.share4dev.info/kb/documents/ 4255.pdf

Li, L. (2010). A Critical Review of Technology Acceptance Literature. Research Paper, Grambling State University. Retrieved January 23, 2017 from: http://www.swdsi.org/ swdsi2010/SW2010_Preceedings/papers/PA104.pdf

List, D. (2003). Participative Marketing for Local radio. Wellington, Original books 
Lucas, H.C.J. and Spitler, V.K. (1999). "Technology Use and Performance: A field Study of Broker Workstations," Decision Sciences (30:2), pp. 291-311.

Madon, S. (2005). Governance lessons from the experience of telecentres in the Kerala. European Journal of Information Systems - Special section. (14) 4, 401-416. Retrieved January 23, 2017 from http://dl.acm.org/citation.cfm?id=1151570

Masiero, S. (2011). Financial vs Social Sustainability of Telecenters: Mutual Exclusion or Mutual Reinforcement. EJISDC 45(3) 1-23. Web. 12 Mar. 2011_Retrieved January 23, 2017 from https://www.ejisdc.org/ojs2.../index.php/ejisdc/article/view/751

Mikkelson, W.H., Partch, M.M., \& Kshitij S. K. (1997). "Ownership and operating performance of companies that go public," Journal of financial economics, (44) 3, 281-307.

National Planning Commission, (2011). National Development Plan: Vision for 2030. Retrieved June 12, http://www.gov.za/sites/www.gov.za/files/devplan_2.pdf

Population Matters, (2017). Sustainable technologies. Retrieved January 23, 2017 from https:// www.populationmatters.org/sustainable-technologies/

Proenza F. J, Bastidas-Buch R. \& Montero G. (2001). Telecenters for socio-economic and rural development in Latin America and the Caribbean. FAO, ITU and IADB, Washington DC, May 2001. Retrieved January 23, 2017 from http://www.iadb.org/sds/itdev/telecenters/ fullrep.pdf

Rickinson, M. \& May, H. (2009). A comparative study of methodological approaches to reviewing literature. The Higher Education Academy, York Science Park, Heslington. Retrieved January 23, 2017 http://www.heacademy.ac.uk/assets/documents/resources/ Comparativestudy.pdf

Roman, R. \& Colle, R (2002). Creating a participatory telecenter enterprise. Retrieved June 2, $2017 \mathrm{http}: / /$ www.share4dev.info/kb/documents/4229.pdf

Shih, H. (2003). Extended technology acceptance model of Internet utilization behavior. https:// pdfs.semanticscholar.org/109f/cb265676d2177db1682469d41f33ae62775c.pdf

Smith, R. (2012). Enabling technologies: Information and communications technology: Digital Doorway installed Down Under. Retrieved January 23, 2017 from http://www.csir.co.za/ enews/2012_nov/06.html

Smith, R. Cambridge, G \& Gush, K. (2006). Digital doorway computer literacy through unassisted learning in South Africa. CSIR Research and Innovation Conference: 1st CSIR Biennial Conference. February 26-27, 2006, pp1

Stillman, L., Herselman, M., Marais, M., Pitse-Boshomane, M., Plantinga, P. \& Walton, S. (2012). Digital Doorway: Social-technological innovation for high-needs communities. EJISDC 50 (2) 1-18, Retrieved January 23, 2017 from http://www.ejisdc.org/ojs2/ index.php/ejisdc/article/viewFile/880/397

Van der Vyver A.G. \& Marais, M.A. (2013). Evaluating users' perceptions of the Digital Doorway: a narrative analysis. Accepted for publication by the Information Technology for Development, 2013.

Venkatesh, V. (2000), Determinants of perceived ease of use: integrating control, intrinsic motivation, and emotion into the technology acceptance model. Information Systems Research, 11 (4), 342-365. 
Venkatesh, V., \& Davis, F. D. (2000). A Theoretical Extension of the Technology Acceptance Model: Four Longitudinal Field Studies. Management Science (46:2), PP. 186-204.

Walsham, G. (2006). Doing interpretive research, European Journal of Information Systems, Retrieved January 23, 2017 from: http://dx.doi.org/10.1057/palgrave.ejis.3000589

Watt, A. (2014). Project Management. Retrieved June 12, 2017 from: https://opentextbc.ca/ projectmanagement/chapter/chapter-5-project-stakeholders-project-management/

Whyte, V.T., (2000). Assessing Community Telecentres: Guidelines for resaerchers, IDRC, Ottawa,

World Commission on Environment and Development (1987). Our Common Future. Oxford: Oxford University Press

Zongo, G. (1999). What is a telecentre? A review of best practice and models, Paper presented at the conference Building the Information Community in Africa, February. 